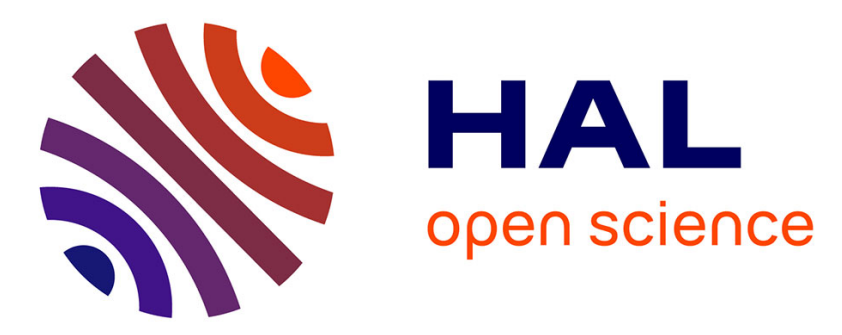

\title{
Application of smoothed particle hydrodynamics (SPH) and pore morphologic model 2 to predict saturated water conductivity from X-ray CT imaging in a silty loam Cambisol
}

N. Dal Ferro, A.G. Strozzi,, Céline Duwig, P. Delmas, P. Charrier, F. Morari,

\section{To cite this version:}

N. Dal Ferro, A.G. Strozzi,, Céline Duwig, P. Delmas, P. Charrier, et al.. Application of smoothed particle hydrodynamics (SPH) and pore morphologic model 2 to predict saturated water conductivity from X-ray CT imaging in a silty loam Cambisol. Geoderma, 2015, 255-256, p. 27-34. 10.1016/j.geoderma.2015.04.019 . ird-01202848

\section{HAL Id: ird-01202848 \\ https://hal.ird.fr/ird-01202848}

Submitted on 21 Sep 2015

HAL is a multi-disciplinary open access archive for the deposit and dissemination of scientific research documents, whether they are published or not. The documents may come from teaching and research institutions in France or abroad, or from public or private research centers.
L'archive ouverte pluridisciplinaire HAL, est destinée au dépôt et à la diffusion de documents scientifiques de niveau recherche, publiés ou non, émanant des établissements d'enseignement et de recherche français ou étrangers, des laboratoires publics ou privés. 


\title{
Q1 Application of smoothed particle hydrodynamics (SPH) and pore morphologic model to predict saturated water conductivity from X-ray CT imaging in a silty loam Cambisol
}

\author{
N. Dal Ferro ${ }^{\text {a,* }}$, A.G. Strozzi ${ }^{\text {b }}$, C. Duwig ${ }^{\text {c }}$, P. Delmas ${ }^{\text {d }}$, P. Charrier ${ }^{\text {e }}$, F. Morari ${ }^{\text {a }}$ \\ a Department of Agronomy, Food, Natural resources, Animals and Environment, Agripolis, University of Padova, Viale Dell'Università 16, 35020 Legnaro, Padova, Italy \\ b UNAM, CCADET, Ciudad Universitaria, Mexico Cuidad, Mexico \\ ' IRD/UJF-Grenoble 1/CNRS/G-INP, LTHE, UMR 5564, BP 53, 38041 Grenoble Cedex 9, France \\ d Department of Computer Science, The University of Auckland, Private Bag 92019, New Zealand \\ e Laboratoire 3S-R, CNRS/UMR/UJF/INP BP 53, 38041 Grenoble Cedex 9, France
}

\section{A R T I C L E I N F O}

\section{Article history:}

Received 24 January 2015

Received in revised form 1 April 2015

Accepted 16 April 2015

Available online $\mathrm{xxxx}$

\section{Keywords:}

X-ray computed microtomography

Saturated hydraulic conductivity

Soil structure

Pore size distribution

\begin{abstract}
A B S T R A C T
This study aims to estimate saturated hydraulic conductivity in a silty loam soil and compare modelled data with 20 experimental ones. The flow characteristics of twelve undisturbed soil cores $(5 \mathrm{~cm}$ in diameter $\times 6 \mathrm{~cm}$ high $)$ were 21 measured in the laboratory after performing X-ray computed microtomography (microCT) analysis. MicroCT 3D 22 imaging was integrated with an existing pore morphologic model and a numerical simulation based on mesh- 23 free smoothed particle hydrodynamics (SPH) to calculate the water flow through the macropore network 24 (pores $>40 \mu \mathrm{m}$ ). Results showed that the proposed SPH method was able to predict hydraulic conductivity of 25 large-sized samples as falling in the range of the experimental ones. By contrast the morphologic model generally 26 underestimated the water flow and was slightly affected by the pore shape. Increasing microCT imaging resolu- 27 tion and expanding the variability with other soil types will improve the understanding of the role of micropore 28 size and morphology on water conductivity.
\end{abstract}

C 2015 Published by Elsevier B.V.

\section{Introduction}

Reliable estimation of fluid flow and transport through porous media is crucial for several disciplines including geosciences and water resources management. Great efforts focused on indirect methods for water flow predictions in porous media which mainly considered the physical media characteristics (specific surface, grain and pore size etc.) (Arya et al., 2010; Kozeny, 1953). However, these methods are suitable for homogeneous and simplified pore networks with little or no organic matter (Chapuis, 2012). Some explicit approaches referring to natural soils are mostly based on regression equations as the pedotransfer functions (PTFs) (Bouma, 1989). Despite the extensive literature (e.g., Pachepsky et al., 2006; Vereecken et al., 2010) and large databases on soil characteristics as a result of PTFs (Leij et al., 1996; Lilly, 1996), the accuracy and reliability of PTFs may be appropriate on regional or national scale, whereas they are not recommended at specific points (plot or microscopic scales) and when soils are outside the type of those used to derive the PTFs (Wösten et al., 2001). Experimental application of Darcy's law is the main direct method to measure the laminar water flow both in laboratory and in the field, which was directly correlated to micro-scale governing equations based on Stokes' law (Bear, 1972). Since recent advances on

\footnotetext{
* Corresponding author.

E-mail address: nicola.dalferro@unipd.it (N. Dal Ferro).
}

experimental analysis and image processing techniques through X-ray 56 computed microtomography (microCT), which allows the reconstruc- 57 tion of real structure properties, pore level models have been developed 58 with the aim to solve partial differential equations using numerical 59 techniques. The great advantage of having inside images of the undis- 60 turbed soil pore network is to overtake the concept of the capillary bun- 61 dle model while studying the soil in its three-dimensional space (Hunt 62 et al., 2013).

Remarkable results were shown by Narsilio et al. (2009) who esti- 64 mated saturated hydraulic conductivity on uniform granular material. 65 Following the derivation introduced by Bear and Bachmat (1990) that 66 links the macroscopic phenomenological Darcy's law and the pore- 67 scale Stokes' equations, the authors estimated successfully the water 68 flow by solving directly the Navier-Stokes equation at the pore scale. 69 However the structural complexity of much more reliable natural soils 70 is very difficult to model as a consequence of high demand of computa- 71 tional work. Moreover, the generation of a quality mesh, prerequisite for 72 accurate numerical simulations, has become time inefficient and 73 expensive.

Alternative approaches, such as Lagrangian particle-based methods, 75 have been proposed with the aim to handle computational load more 76 easily and speed up computer simulations. Lattice-Boltzmann, diffuse 77 element method (DEM) and smoothed particle hydrodynamics (SPH) 78 are mesh-free computer simulation techniques, easy to design and suit- 79 able for random and deformable porous media (Liu and Liu, 2003). SPH 80 
is promising for direct simulation of multi-phase material behaviour at multiple scale (Liu and Liu, 2010). As such it is particularly well adapted to simulating flow and flow-solid multi-scale interaction in real porous structure by linking observed soil structure and its transport function. Due to its molecular structure, SPH modelling can make the best out of parallel implementation on GPGPU (general purpose graphic processing units). Known weaknesses of SPH modelling are the complexity of interaction at multi-phase interfaces. Despite the growing interest on mesh free methods, only a few have combined this computational approach to soil science in order to quantify physical characteristics on large and complex samples. Ovaysi and Piri (2010) developed a moving particle semi-implicit method (MPS) and modelled the permeability of a reservoir sandstone previously analysed with X-rays. The authors successfully predicted the intrinsic permeability and validated their model against experimental data. However the representative elementary volume was reduced to $c a .1 \mathrm{~mm}^{3}$ as a result of the uniform pore and throat size (mostly 20-30 $\mu \mathrm{m}$ ) in sandstone. Tartakovsky and Meakin (2005), using a numerical model based on smoothed particle hydrodynamic, focused on the three-dimensional fluid flow prediction on fractures generated by self-affine fractal surfaces. They stated that the mesh-free approach was suitable for simulating the surface flow of both wetting and non-wetting fluids in complex fractures, although they also highlighted the need of comparison with laboratory measurements and the application of their model to soil samples that should include a wider pore size distribution. In fact, the assumptions of homogeneity of hydraulic properties are often not met in natural intact samples due to high variability of structure properties. In order to avoid computational complexity in calculating saturated permeability $\left(\mathrm{K}_{\mathrm{S}}\right)$ of soil cores, Elliot et al. (2010) used 3D pore characteristics derived from Xray microCT in modified pore fluid transport models (e.g. Darcy's law and Poiseuille's equation), demonstrating the advanced potentialities of the 3D approach.

Our hypothesis is that X-ray microCT can be used to calculate saturated conductivity on large complex soil structures by coupling the quantification of pore network properties and modelling. As a result in this work we compared two different approaches to simulate saturated conductivity using 3D-derived pore information, one based on an innovative numerical model based on smoothed particle hydrodynamic (SPH) and the other based on Darcy's law and modified Poiseuille's equation according to Elliot et al. (2010).

\section{Materials and methods}

\subsection{Soil sampling}

The soil samples come from a long-term experiment established in 1962 at the experimental farm of the University of Padova (Italy). The soil is a silty loam Fluvi-Calcaric Cambisol (CMcf) (FAO-UNESCO, 1990). This work considered four treatments characterized by different fertilizations: organic, mineral and no fertilization. Organic fertilizations were farmyard manure (FMY; $60 \mathrm{t} \mathrm{ha}^{-1} \mathrm{y}^{-1}, 20 \%$ d.m.) and liquid manure (L; $120 \mathrm{t} \mathrm{ha}^{-1} \mathrm{y}^{-1}, 10 \%$ d.m.); mineral input (NPK) was $300 \mathrm{~kg} \mathrm{~N} \mathrm{ha}^{-1} \mathrm{y}^{-1}, 66 \mathrm{~kg} \mathrm{P} \mathrm{ha}^{-1} \mathrm{y}^{-1}, 348 \mathrm{~kg} \mathrm{~K} \mathrm{ha}^{-1} \mathrm{y}^{-1}$ while no fertilization control had no inputs ( 0 ). Liquid manure input also includes crop residue incorporation ( $\mathrm{r}=3.7 \mathrm{t} \mathrm{Cha}^{-1} \mathrm{y}^{-1}$ on average). The same type of soil tillage has been used in all treatments, with autumn ploughing and subsequent cultivations before sowing the main crop. The experimental layout is a randomized block with three replicates, on plots of $7.8 \times 6 \mathrm{~m}$. Further details on experimental design are extensively reported in the literature (e.g., Morari et al., 2006). Twelve (4 treatments $\times 3$ replicates, hereafter indicated with subscripts 1,2 , 3 ) undisturbed soil cores ( $5 \mathrm{~cm}$ diameter, $6 \mathrm{~cm}$ length) were collected in August 2010, at the end of the maize season, from the topsoil ( 5 to $20 \mathrm{~cm}$ depth) in polymethylmethacrylate (PMMA) cylinders using a manual hydraulic core sampler (Eijkelkamp, The Netherlands). Successively soil cores were stored at $5{ }^{\circ} \mathrm{C}$ before analysis.

\subsection{X-ray microtomography and digital image processing and analysis}

Soil core scanning was completed at the "3S-R" laboratory in Greno- 145 ble (http://www.3sr-grenoble.fr). The X-ray generator was a multi- 146 energy and different spot size (Hamamatsu), with a voltage range of 147 $40-150 \mathrm{kV}$ and intensity of $0-500 \mu \mathrm{A}$. The beam open angle was $43^{\circ} .148$ The detector had the dimension of $1920 \times 1536$ pixels. All samples 149 were scanned with the same technical parameters that were calibrated 150 as a function of sample dimension, composition and distance from the 151 $\mathrm{X}$-ray beam generator. Setting parameters were $100 \mathrm{kV}, 300 \mu \mathrm{A}$ and pro- 152 jections were collected during a $360^{\circ}$ sample rotation at $0.3^{\circ}$ angular in- 153 cremental step. Each angular projection was calculated as the mean of 154 10 repeated acquisitions. The scan frequency was 7 images $s^{-1}$. Projec- 155 tions were reconstructed using the dedicated software DigiCT 1.1156 (Digisens, France) to obtain a stack of about 1500 2D slices in 32-bit 157 depth. 32-bit images were later converted into 8-bit depth. Final voxel 158 resolution was $40 \mu \mathrm{m}$ in all three directions.

159

The digital image processing and analysis were conducted with the 160 public domain image processing ImageJ (Vs. 1.45, National Institute of 161 Health, http://rsb.info.nih.gov/ij). In order to exclude the PMMA sample 162 holder and artefacts caused by edge effects, a cylindrical 3D image 163 dataset, almost equal to the entire soil column, was selected for analysis. 164 The volume had a diameter of 1150 pixels (the original soil cores were 165 1250 pixels in diameter) and was composed of 1200 slices.

166

Slices were segmented using a global-threshold value based on the 167 histogram greyscale that was determined by the maximum entropy 168 threshold algorithm. The threshold value was selected where the 169 inter-class entropy was maximized (Luo et al., 2010). Using 8- 170 connectivity, a mathematical morphology closing operator (Serra, 171 1982) of half-width of 1 was applied to the binary images to fill 172 misclassified pixels inside the pores as well as to maintain pore connec- 173 tions. The structure characterization of 3D stacks included the estima- 174 tion of total porosity, pore size distribution, tortuosity $(\tau)$ and discrete 175 compactness $\left(C_{d}\right)$. BoneJ plugin (Doube et al., 2010), freely available 176 for ImageJ, was used to reconstruct a 3D pore skeleton (Lee et al., 177 1994) for each sample to determine pore tortuosity as the ratio between 178 the actual pore length and the Euclidean distance along the skeleton. 179 The discrete compactness is a 3D shape factor defined on a scale of 1180 (circular or spherical) to 0 (linear or disperse structure) which provides 181 information on the morphology of basic shapes that have been used to 182 represent structures in 3D CT imagery. It was introduced to estimate 183 the pore hydraulic radius as per Bribiesca et al. (2003):

$$
C_{d}=\frac{A_{C}-A_{C \min }}{A_{C \max }-A_{C \min }}
$$

where $A_{c}$ is the contact surface area, $A_{c m i n}$ is the minimum contact sur- 186 face area and $A_{C \max }$ is the maximum contact surface area (Bribiesca, 2000).

3D pore size distribution was calculated using CTAn software v. 188 1.12.0.0 (Bruker micro-CT, Kontich, Belgium) from each binarized 189 stack, drawing a sphere inside the 3D pore space that touched the bor- 190 dering soil matrix and measuring the sphere diameter. The method first 191 identifies the medial axes of all structures and then the sphere-fitting is 192 done for all the voxels lying along this axis (Remy and Thiel, 2002). 193

\subsection{Experimental saturated conductivity $\left(K_{S}\right)$ estimate}

After microCT scanning, soil samples were gradually saturated from 195 the bottom up over a 5-day period using temperature-equilibrated tap 196 water. Saturated hydraulic conductivity $\left(\mathrm{K}_{\mathrm{S}}, \mathrm{m} \mathrm{s}^{-1}\right)$ was measured 197 using the constant head or falling head method, depending on the soil 198 characteristics and range of $K_{S}$ that can be measured (Reynolds et al., 199 2002). 


\subsection{Water retention curve estimate}

After $\mathrm{K}_{\mathrm{S}}$ measurements, the cores were subjected to water retention curve estimate using the Ku-pF apparatus (UGT GmbH, Müncheberg, Germany). Briefly, after saturation two tensiometers were installed at depths of $-1.5 \mathrm{~cm}$ and $-4.5 \mathrm{~cm}$, respectively, from the sample surface. The samples were sealed at the bottom and placed in the apparatus for the combined measurement of sample mass and matric potentials, from which the water retention curves were estimated. Finally, experimental data were interpolated according to the Van Genuchten model (Van Genuchten et al., 1991) using RETC version 6.02. The water retention curves (WRCs) were then used to determine the pore size distribution (PSD) according to the capillary model and the equivalent pore radii were calculated from the matric head by applying the Young-Laplace equation:

$r=\frac{2 \gamma \cos \theta}{P}$

where $r$ is the pore radius, $P$ is the matric head, $\gamma$ is the surface tension of water at $20^{\circ} \mathrm{C}\left(0.7286 \mathrm{~N} \mathrm{~m}^{-1}\right)$ and $\theta$ is the contact angle between water and soil (here it was considered to be $0^{\circ}$ ). Total pore volume was also measured with the gravimetric method as a result of soil cores weighing at saturation and after oven-drying for $24 \mathrm{~h}$ at $105^{\circ} \mathrm{C}$.

\subsection{Smoothed particle hydrodynamic (SPH) model description and simulations}

Smoothed Particle Hydrodynamics (SPH) considers a multi-phase object as a set of particles each representing a discrete volume fraction of the studied object. Each particle has its own mechanical properties summarizing its individual behaviour as governed by the laws of hydrodynamics (Monaghan, 1992).

The physical properties (mass, velocity, energy) of a SPH particle at a given location are approximated by a generic quantity $A$. $A$ is computed by taking into account the set of discrete particles $i$, with $i=1, \ldots, N$, constituting the SPH volume. The value of $A(i)$ for any given particle $i$ depends on all the neighbourhood particles $j$, the group of which is formed from all the particles constituting the SPH volume, excluding the particle $i$ within a distance $h$ from the particle centred in $r_{i}$ :

$A(i)=\sum_{j \neq i} A(j) W\left(r_{i}-r_{j}, h\right)$,

where $W\left(r_{i}-r_{j}, h\right)$ is a smoothing kernel function value at distance $r_{i}-r_{j}$. W controls how the particle $j$ inside the smoothing distance $h$ influences the particle $i$. This function is solved for all the particle $i$ defining the fluid volume. Classically $W$ is often chosen as a cubic spline or Gaussian curve. To simulate the velocity $q$ of fluid particles, incompressible fluid movement was described using a simplified Navier-Stokes equation and interactions between particles were expressed with Hooke's law (Strozzi et al., 2009):

$\rho\left(\frac{\partial v}{\partial t}+v \cdot \nabla v\right)=-\nabla p+\rho g+\mu \nabla^{2} v$

where $\rho$ is the fluid density, $v$ is the flow velocity, $p$ is the pressure, $\mu$ is the dynamic viscosity and $g$ the gravity at sea-level. The numerical solution of Navier-Stokes equations with the SPH method was implemented as in Liu and Liu (2003).

\subsubsection{SPH numerical simulation, initial and limit conditions}

Due to given memory requirements, one voxel contains one particle as a sphere. The number of particles within each simulated pores varied depending on its volume. The volume of interaction for each particle with its neighbours was set as a cube of
$5 \times 5 \times 5$ voxels for a calculated radius $r_{i}$ equal to $100 \mu \mathrm{m}$. The mass 252 $m_{i}$ of the particle is the equivalent mass of spherical particle of 253 radius $=20 \mu \mathrm{m}(0.5$ voxels $)$ and equals to $3.2 \cdot 10^{-9} \mathrm{~g}$. The dynamic 254 viscosity $\mu$ was set at 0.001 Pa s. For each pore, the inlet and outlet 255 were chosen as cross-sections (planes perpendicular) to the pore 256 skeleton upper and lower extremities. The initial condition for the 257 flow simulation considers the pores filled with water and assigned 258 the inlet and outlet cross-sections to the voxels belonging to the 259 top and bottom skeleton cross-sections. The pressure difference $\Delta P 260$ between the plane inlet and the outlet was set at 1 Pa which ensures 261 that the Reynolds number is equal or lower than 10, and thus is com- 262 fortably in the laminar regime (Narsilio et al., 2009). Once SPH flow 263 simulation in the pores reached permanent state, the flow was com- 264 puted by summing (integrating) the velocities of all pores across the 265 outlet cross sections. The saturated hydraulic conductivity $\mathrm{K}_{\mathrm{SPH}}$ was 266 obtained through the Darcy's equation:

$\mathrm{K}=\frac{Q L}{A \Delta P}$,

where $Q$ is the flow through the pores, $A$ is the cross-sectional area of 269 the sample, $L$ is the sample length and $\Delta P$ is the change in hydrostatic pressure. $K_{S P H}$ was calculated for the pores representing the highly 270 networked massive singular pore through the entire soil cores 271 (Fig. 1; Table 1).

\subsection{K estimate from pore morphologic characteristics}

Saturated hydraulic conductivity of the largest pore (K $\mathrm{K}_{\mathrm{MORPHO}}$ ) with- 274 in each stack, representing the highly networked massive singular pore 275 within the soil cores (Dal Ferro et al., 2013), was calculated following 276 the morphologic approach proposed by Elliot et al. (2010). The novelty 277 of the model consisted in combining three dimensional pore shape as- 278 pects (i.e. tortuosity and discrete compactness) with the pore volume 279 and using that information in Darcy's equation (Eq. (5)) and a modified 280 Poiseuille equation.

The water flow through the pores $(Q)$ was estimated with a 282 modified Poiseuille equation (Elliot et al., 2010) as follows:

$Q=\frac{\pi R^{4} \Delta P}{8 L_{c} \nu}$

where $R$ is the pore radius, $v$ is the viscosity of water at room tempera- 285 ture and $L_{c}$ is the complete pore length. $R$ and $L_{c}$ were estimated adopting the approach of Elliot et al. (2010) in order to incorporate 286 the pore characteristics in the established model as follows:

$R={\frac{V}{\pi L_{C}{ }^{c}}}^{1 / 2}$

where $V$ is the pore volume and

$L_{c}=\left[\left(1-C_{d}\right) \tau L\right]$,

where $L$ is the length of soil core, $C_{d}$ is the discrete compactness of pore and $\tau$ is the tortuosity (see Section 2.2).

\subsection{Water conductivity estimate based on the Kozeny-Carman equation}

Experimental and modelled water conductivity data were com- 292 pared with those from a semi-empirical modified Kozeny-Carman 293 equation (Rawls et al., 1998), which uses soil porosity and pore 294 size distribution data to estimate the saturated hydraulic conductiv- 295 ity $\left(\mathrm{K}_{\mathrm{KC}}\right)$ as follows:

$\mathrm{K}_{\mathrm{KC}}=C \phi_{e}^{3-\lambda}$ 

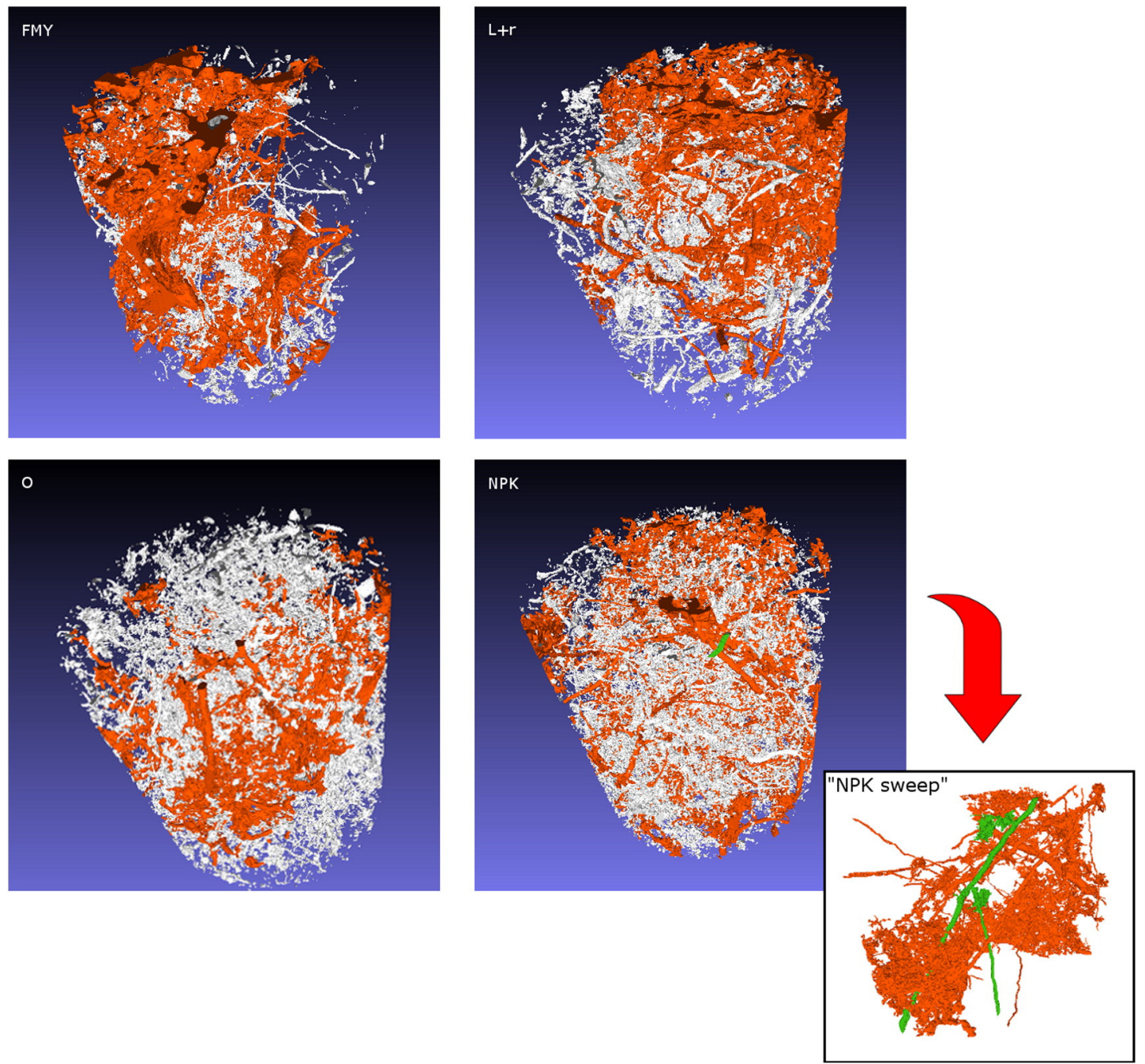

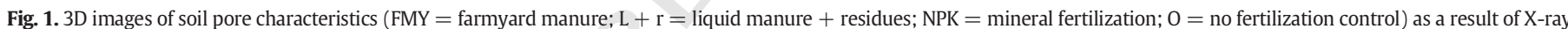

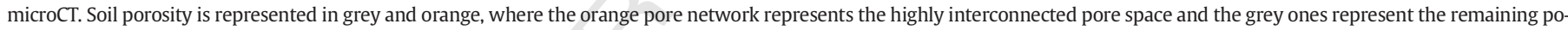

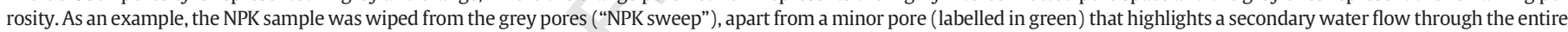
soil core. (For interpretation of the references to color in this figure legend, the reader is referred to the web version of this article.)

where $\phi_{e}$ is the effective porosity (total porosity minus water content at $-33 \mathrm{kPa} ; \mathrm{m}^{3} \mathrm{~m}^{-3}$ ), $C$ is an empirically derived constant (5.36 $\cdot 10^{-4} \mathrm{~m} \mathrm{~s}^{-1}$, Rawls et al., 1998) and $\lambda$ is the Brook and
Corey pore size distribution index, corresponding to the Van 300 Genuchten pore size distribution parameter $n$ minus 1 (Maidment, 301 1993).

Table 1

Structure properties of soil cores.

\begin{tabular}{|c|c|c|c|c|c|c|c|c|c|c|c|}
\hline \multirow[t]{2}{*}{ Sample ID } & \multicolumn{3}{|c|}{ Texture parameters } & \multicolumn{4}{|c|}{ WRC parameters ${ }^{\mathrm{a}}$} & \multicolumn{4}{|l|}{ MicroCT parameters } \\
\hline & Sand (\%) & Silt (\%) & Clay (\%) & $\theta_{\mathrm{r}}$ & $\theta_{\mathrm{s}}$ & $\alpha$ & $\mathrm{n}$ & Total porosity $\left(\mathrm{m}^{3} \mathrm{~m}^{-3}\right)$ & Largest pore $\left(\mathrm{m}^{3} \mathrm{~m}^{-3}\right)$ & $C_{d}^{\mathrm{b}}$ & $\tau^{c}$ \\
\hline $\mathrm{FMY}_{1}$ & 41.9 & 54.1 & 4.0 & 0.180 & 0.490 & 0.031 & 1.210 & 0.058 & 0.053 & 0.91 & 4.72 \\
\hline $\mathrm{FMY}_{2}$ & 30.4 & 64.6 & 4.9 & 0.000 & 0.461 & 0.024 & 1.168 & 0.117 & 0.104 & 0.85 & 4.36 \\
\hline $\mathrm{FMY}_{3}$ & 30.5 & 64.3 & 5.1 & 0.172 & 0.476 & 0.062 & 1.198 & 0.045 & 0.031 & 0.88 & 6.35 \\
\hline $\mathrm{L}+\mathrm{r}_{1}$ & 35.5 & 59.8 & 4.6 & 0.000 & 0.532 & 0.025 & 1.173 & 0.170 & 0.163 & 0.96 & 4.47 \\
\hline $\mathrm{L}+\mathrm{r}_{2}$ & 39.2 & 56.6 & 4.2 & 0.000 & 0.515 & 0.148 & 1.096 & 0.063 & 0.052 & 0.86 & 5.51 \\
\hline $\mathrm{L}+\mathrm{r}_{3}$ & 34.7 & 61.1 & 4.1 & 0.000 & 0.481 & 0.016 & 1.138 & 0.015 & 0.008 & 0.95 & 3.75 \\
\hline $\mathrm{NPK}_{1}$ & 31.8 & 62.3 & 5.9 & 0.136 & 0.500 & 0.056 & 1.191 & 0.078 & 0.068 & 0.87 & 5.20 \\
\hline $\mathrm{NPK}_{2}$ & 28.1 & 66.6 & 5.3 & 0.000 & 0.492 & 0.060 & 1.106 & 0.058 & 0.045 & 0.84 & 5.30 \\
\hline $\mathrm{NPK}_{3}$ & 32.8 & 61.8 & 5.4 & 0.000 & 0.521 & 0.097 & 1.091 & 0.051 & 0.036 & 0.87 & 4.37 \\
\hline $\mathrm{O}_{1}$ & 25.0 & 69.6 & 5.4 & 0.000 & 0.459 & 0.056 & 1.058 & 0.037 & 0.020 & 0.84 & 6.58 \\
\hline $\mathrm{O}_{2}$ & 40.9 & 54.2 & 4.9 & 0.000 & 0.432 & 0.011 & 1.181 & 0.062 & 0.047 & 0.81 & 6.35 \\
\hline $\mathrm{O}_{3}$ & 34.3 & 60.5 & 5.2 & 0.190 & 0.439 & 0.085 & 1.203 & 0.035 & 0.034 & 0.88 & 2.82 \\
\hline
\end{tabular}

${ }^{a}$ Water retention curve (WRC) parameters according to the Van Genuchten model.

b Discrete compactness.

c Tortuosity. 


\section{Results and discussion}

\subsection{Soil structure properties}

Total porosity ranged between a minimum of $0.432 \mathrm{~m}^{3} \mathrm{~m}^{-3}$ and a maximum of $0.532 \mathrm{~m}^{3} \mathrm{~m}^{-3}$ in the control $\left(\mathrm{O}_{2}\right)$ and liquid manure treatment $\left(\mathrm{L}+\mathrm{r}_{1}\right)$, respectively. By contrast microCT porosity excluded all the pores smaller than $40 \mu \mathrm{m}$ (Table 1) due to resolution limits and showed a total porosity of $0.066 \mathrm{~m}^{3} \mathrm{~m}^{-3}$ on average, varying from a minimum of $0.015 \mathrm{~m}^{3} \mathrm{~m}^{-3}$ and a maximum of $0.170 \mathrm{~m}^{3} \mathrm{~m}^{-3}$, both in $\mathrm{L}+\mathrm{r}$. Pore size distribution (PSD), estimated from water retention curves according to the Young-Laplace capillary model, highlighted that soil porosity was mainly composed by pores $<40 \mu \mathrm{m}$ as they represented $81.4 \%$ of total porosity, on average (Fig. 2a). Conversely microCT allowed only the analysis of pores $>40 \mu \mathrm{m}$ (Fig. 2b), showing that the macropores were mostly distributed in the range of $40-1040 \mu \mathrm{m}$ (86.0\% on average) according to the PSD classification of Brewer (1964). An outlier was identified with microCT in the sample $\mathrm{L}+\mathrm{r}$ since a large pore, included during sampling, drastically increased both total porosity and pores larger than $1040 \mu \mathrm{m}$, biasing the representativeness of the core. MicroCT was able to detect such pore allowing for the visualization of the complex pore network larger than $40 \mu \mathrm{m}$ while the WRC, that is based on the simple capillary bundle model (Hunt et al., 2013), probably overestimated the smaller pores due to the presence of "ink-bottle" necks.

X-ray analyses showed that microCT porosity within the soil samples was composed by a highly interconnected pore space (Table 1) that involved a high degree of connectivity between the voids (Dal Ferro et al., 2013), describing the main pore structure that spanned the soil cores (Fig. 1). For this reason $\mathrm{K}_{\mathrm{MORPHO}}$ and $\mathrm{K}_{\mathrm{SPH}}$ were calculated within such void network since it represented a pore continuity between the top and the bottom of each soil core. The discrete
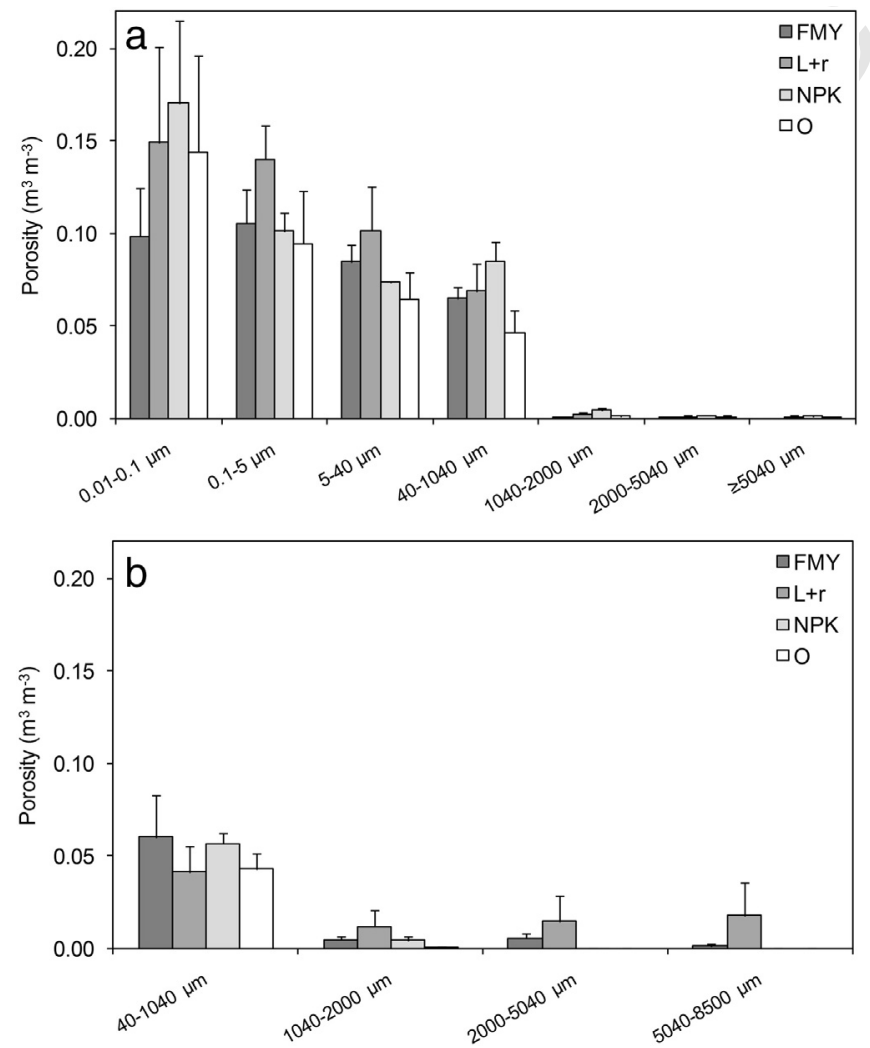

Fig. 2. Pore size distribution $\left(\mathrm{m}^{3} \mathrm{~m}^{-3}\right.$ ) estimated by means of (a) water retention curves and (b) X-ray microtomography. FMY $=$ farmyard manure, $\mathrm{L}+\mathrm{r}=$ liquid manure + residues, NPK $=$ mineral fertilization and $\mathrm{O}=$ no fertilization control treatments. compactness $\left(C_{d}\right)$ of the massive singular pore, establishing a relation- 333 ship between the surface/volume ratio and the pore radius and contrib- 334 uting to hydraulic conductivity (Elliot et al., 2010), was always $\geq 0.81335$ (Table 1). While the massive singular pore did bridge the entire soil 336 core, $C_{d}$ indicated that the shape of the whole pore system was fairly 337 spherical and could be described a single sphere (Bribiesca, 2008). Nev- 338 ertheless, this parameter does not exclude concave regions or multiple- 339 branch pores, although their structure might not be described by a cap- 340 illary bundle model as also recently discussed by Hunt et al. (2013). 341 Conversely, the pore system could have pore-pathways in all regions 342 of the sample volume (Elliot et al., 2010). Finally, tortuosity of the 343 pore space was 4.98 on average, which meant that the actual pore 344 path was $c a$. five times larger than core height.

\subsection{Hydraulic conductivity}

Experimental saturated hydraulic conductivity values $\left(\mathrm{K}_{\mathrm{S}}\right)$ ranged 347 from a minimum of $1.90 \cdot 10^{-6} \mathrm{~m} \mathrm{~s}^{-1}$ and a maximum of 348 $4.27 \cdot 10^{-5} \mathrm{~m} \mathrm{~s}^{-1}$, which is in line with previously reported values 349 for the same soils (Morari, 2006). $\mathrm{K}_{\mathrm{SPH}}$ data were similar to those exper- 350 imentally measured at saturation, on average (geometric mean) 351 $5.03 \cdot 10^{-6} \mathrm{~m} \mathrm{~s}^{-1}$ (Table 2) and varying between two orders of magni- 352 tude $\left(10^{-5}-10^{-6} \mathrm{~m} \mathrm{~s}^{-1}\right)$, while lower values were found with the mor- 353 phologic approach $\left(\mathrm{K}_{\text {МоRРно }}=1.26 \cdot 10^{-6} \mathrm{~m} \mathrm{~s}^{-1}\right)$. When modelled 354 data were plotted vs. the experimental ones, a poor correlation was gen- 355 erally observed between the values. The correlation coefficient $\left(R^{2}\right)$ var- 356 ied between 0.098 and 0.790 , with the best correlation found between 357 $\mathrm{K}_{\mathrm{MORPHO}}$ and $\mathrm{K}_{\mathrm{KC}}$. The poor correlation can be explained by the lack of 358 diversity in the soil texture. Indeed the soil cores here analysed were 359 characterized by similar texture properties (silty loam) as affected by 360 the same pedogenic processes, making it difficult to distinguish be- 361 tween the subtle structure changes of each sample and, in turn, their in- 362 fluence on water flow. Moreover, a reduction of modelled water 363 conductivity (Fig. 3) was noticeable when the soil structure was largely 364 composed of thin pores that are often insufficiently imaged with 365 microCT and thus underrepresented (e.g. in the control samples), espe- 366 cially in the vicinity of grain contacts (Andrä et al., 2013). By contrast, 367 total porosity was a significant parameter for $\mathrm{K}_{\text {MORPHO }}$ estimations. 368 This was highlighted by the strong correlation between $\mathrm{K}_{\text {MORPHo }}$ and 369 total porosity (both from WRC and microCT, Table 3), and particularly 370 emphasized when looking at Fig. $3 \mathrm{~b}$ : in fact the $\mathrm{O}_{1}$ and $\mathrm{O}_{2}$ samples 371 had both the lowest porosity and water conductivity; conversely 372 $\mathrm{L}+\mathrm{r}_{1}$ was characterized by the highest porosity and $\mathrm{K}_{\mathrm{MORPHO}}$, suggest- 373 ing the strong modelled water flow dependency on the total porosity. 374

Table 2

Comparison between the experimental hydraulic conductivity values $\left(\mathrm{K}_{\mathrm{S}}\right)$ and those pre- $t 2.2$ dicted using SPH ( $\mathrm{K}_{\mathrm{SPH}}$ ) and the morphologic model ( $\mathrm{K}_{\mathrm{MORPHO}}$ ) proposed by Elliot $\mathrm{t} 2.3$ et al.(2010) and modified Kozeny-Carman equation ( $\left.\mathrm{K}_{\mathrm{KC}}\right)$.

\begin{tabular}{lcccc}
\hline \multirow{2}{*}{ Soil Sample ID } & \multicolumn{4}{c}{ Hydraulic conductivity $\left(10^{-6} \mathrm{~m} \mathrm{~s}^{-1}\right)$} \\
\cline { 2 - 5 } & \multicolumn{1}{c}{$\mathrm{K}_{\mathrm{S}}$} & \multicolumn{1}{c}{$\mathrm{K}_{\mathrm{SPH}}$} & $\mathrm{K}_{\text {MORPHO }}$ & $\mathrm{K}_{\mathrm{KC}}$ \\
\hline $\mathrm{FMY}_{1}$ & $6.31^{\mathrm{a}}$ & 11.50 & 5.17 & 1.81 \\
$\mathrm{FMY}_{2}$ & $2.41^{\mathrm{b}}$ & 10.50 & 4.13 & 2.07 \\
$\mathrm{FMY}_{3}$ & $7.41^{\mathrm{a}}$ & 6.30 & 1.74 & 2.46 \\
$\mathrm{~L}+\mathrm{r}_{1}$ & $9.10^{\mathrm{a}}$ & 10.00 & 40.29 & 4.53 \\
$\mathrm{~L}+\mathrm{r}_{2}$ & $42.74^{\mathrm{a}}$ & 4.61 & 3.88 & 2.84 \\
$\mathrm{~L}+\mathrm{r}_{3}$ & $3.40^{\mathrm{b}}$ & 1.20 & 0.28 & 1.00 \\
$\mathrm{NPK}_{1}$ & $17.50^{\mathrm{a}}$ & 22.70 & 6.24 & 2.09 \\
$\mathrm{NPK}_{2}$ & $9.83^{\mathrm{a}}$ & 2.78 & 0.35 & 1.87 \\
$\mathrm{NPK}_{3}$ & $27.03^{\mathrm{a}}$ & 5.15 & 2.84 & 2.19 \\
$\mathrm{O}_{1}$ & $5.27^{\mathrm{b}}$ & 2.40 & 0.04 & 0.31 \\
$\mathrm{O}_{2}$ & $2.22^{\mathrm{b}}$ & 7.59 & 0.16 & 0.86 \\
$\mathrm{O}_{3}$ & $1.90^{\mathrm{b}}$ & 1.04 & 0.25 & 1.39 \\
Geometric mean $^{\mathrm{b}}$ & 7.06 & 5.03 & 1.26 & 1.64 \\
\hline
\end{tabular}

\footnotetext{
a Constant head method.
}

b Falling head method. 


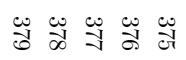
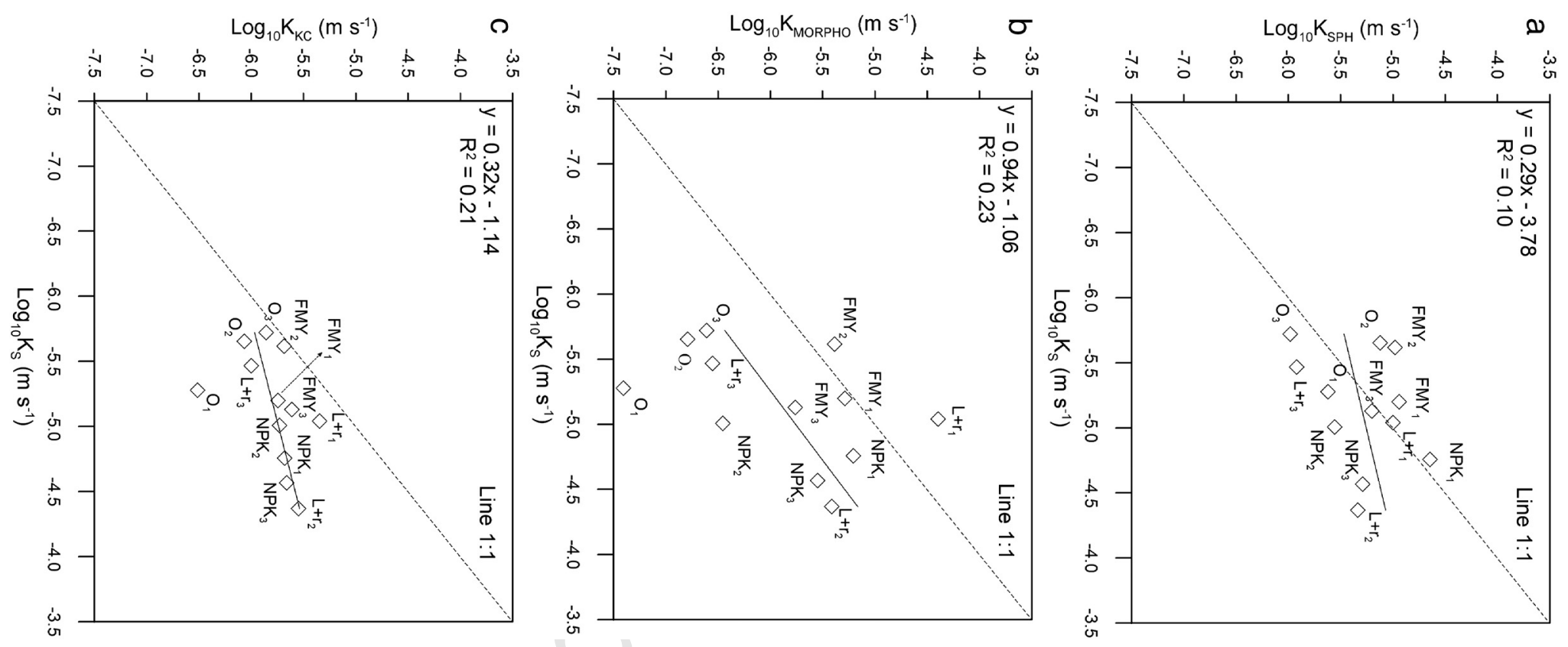

Table 3

Correlation matrix between saturated hydraulic conductivity values and soil structure parameters determined by means of water retention curves (WRC) and microCT. P-values are reported in superscript numbers.

WRC MicroCT

Total porosity Pore size class

Total porosity

Largest Pore size class

$\left(\mathrm{m}^{3} \mathrm{~m}^{-3}\right)$

$\left(\mathrm{m}^{3} \mathrm{~m}^{-3}\right)$

$\left(\mathrm{m}^{3} \mathrm{~m}^{-3}\right)$

pore $(\%) \quad\left(\mathrm{m}^{3} \mathrm{~m}^{-3}\right)$

\begin{tabular}{|c|c|c|c|c|c|c|c|c|c|c|c|c|c|c|c|c|}
\hline & & $\begin{array}{l}0.01-0.1 \\
0.42\end{array}$ & $0.1-5$ & $5-40$ & 40-1040 & $1040-2000$ & $2000-5040$ & $\geq 5040$ & & & $40-1040 \mu \mathrm{m}$ & $1040-2000 \mu \mathrm{m}$ & $2000-5040 \mu \mathrm{m}$ & $5040-8500 \mu \mathrm{m}$ & & \\
\hline $\mathrm{K}_{\mathrm{S}}$ & $\begin{array}{l}0.83^{0.01} \\
0.34^{0.29}\end{array}$ & $0.26^{0.42}$ & $-0.13^{0.68}$ & $-0.03^{0.92}$ & $0.72^{0.01}$ & $0.65^{0.02}$ & $0.46^{0.13}$ & $0.81^{0.01}$ & $0.10^{0.77}$ & $0.03^{0.93}$ & $0.02^{0.94}$ & $0.24^{0.44}$ & $0.09^{0.79}$ & 0.050 .87 & $0.22^{0.49}$ & $0.03^{0.92}$ \\
\hline $\mathrm{K}_{\mathrm{SPH}}$ & $0.34^{0.29}$ & $-0.35^{0.26}$ & $0.20^{0.54}$ & $0.45^{0.15}$ & $0.36^{0.24}$ & $0.28^{0.37}$ & $-0.14^{0.66}$ & $0.14^{0.66}$ & $0.62^{0.03}$ & $0.42^{0.18}$ & $0.64^{0.02}$ & $0.49^{0.11}$ & & 0.250 .43 & $0.34^{0.28}$ & $-0.07^{0.82}$ \\
\hline $\mathrm{K}_{\text {MORPHO }}$ & $0.73^{0.01}$ & $-0.48^{0.12}$ & $0.29^{0.36}$ & $0.66^{0.02}$ & $0.62^{0.03}$ & $0.27^{0.40}$ & $-0.02^{0.96}$ & $0.23^{0.47}$ & $0.73^{0.01}$ & $0.62^{0.03}$ & $0.42^{0.18}$ & $0.77^{0.00}$ & $0.62^{0.03}$ & 0.570 .05 & $-0.22^{0.49}$ & $0.48^{0.11}$ \\
\hline $\mathrm{K}_{\mathrm{KC}}$ & $0.66^{0.02}$ & $-0.45^{0.14}$ & $0.26^{0.42}$ & $0.58^{0.05}$ & $0.71^{0.01}$ & $0.29^{0.37}$ & $0.20^{0.52}$ & $0.27^{0.39}$ & $0.59^{0.04}$ & $0.65^{0.02}$ & $0.32^{0.31}$ & $0.61^{0.04}$ & $0.53^{0.08}$ & 0.470 .12 & $-0.29^{0.35}$ & $0.41^{0.19}$ \\
\hline
\end{tabular}


$2.22 \cdot 10^{-6} \mathrm{~m} \mathrm{~s}^{-1}$ ) (Table 2 ). By contrast, the lower $\mathrm{K}_{\text {MORPHo }}$ values than the experimental ones suggested the model inability to estimate water conductivity of soil-pore structures with a complex geometry. Similar results were also reported by Elliot et al. (2010), showing a general underestimation of modelled data with respect to the experimental ones as a result of potential preferential flow pathways which were not incorporated in the 3D image dataset. Positive correlations (Table 3) were observed between modelled water flow values and large-sized microCT PSD classes which emphasize the importance of conducting macropores (equivalent radius $\mathrm{ca}$. $>400 \mu \mathrm{m}$ ) on water flow dynamics as reported in Jarvis (2007) and Beven and Germann (1982). However, no clear association was observed between more connected macropores and the increase of their size as was reported for some loamy and clayey soils (Larsbo et al., 2014), thus questioning the role of soil macropores on water flow dynamics. Most likely, $\mathrm{K}_{\mathrm{SPH}}$ and $\mathrm{K}_{\mathrm{MORPHO}}$ were also affected by the image resolution since water flow was estimated only for pores $>40 \mu \mathrm{m}$. Some authors (Peng et al., 2014) have reported a minor contribution of small pores on water permeability at a resolution $<12 \mu \mathrm{m}$, although in our case the invisible pores $<40 \mu \mathrm{m}$ would have partially increased the water flow as they might act in two ways: a) the fluid flow is affected by the pore size channels and the prevalence of pores beyond the limits of microCT resolution (Fig. 2a) masked their effect on the fluid flow (Elliot et al., 2010); b) the massive singular pore through the entire soil core may have been even 403 larger with a higher resolution of scanning, expanding the principal 404 connected pore space and thus enhancing its representativeness of the 405 sample (Blunt et al., 2013). For instance, the unconnected pores through 406 the soil core NPK and represented in Fig. 1 (called "NPK sweep", orange 407 and green pores) would have benefited of a higher scanning resolution 408 ensuring their connection and improving water flow prediction to reach 409 the experimental one. Moreover, $\mathrm{K}_{\mathrm{SPH}}$ was affected by the pore connec- 410 tions as the water flow tended to zero where the pores were blind and 411 water could not pass through them (Fig. 4, pores coloured in blue), re- 412 ducing the overall hydraulic conductivity. Finally, according to the 413 Stokes' law pore size affected the viscous forces which in turn grew 414 from the centre of the pores (high velocity, pores coloured in red) to 415 the solid surfaces of the soil matrix (pores coloured in blue) and reduced 416 the SPH water velocity (Fig. 4).

Finally, experimental $\mathrm{K}_{\mathrm{S}}$ and modelled results from microCT analysis 418 were compared with data $\left(\mathrm{K}_{\mathrm{KC}}\right)$ as determined by the Kozeny-Carman 419 equation (Table 2), showing a consistent underestimation of $\mathrm{K}_{\mathrm{KC}}$ with 420 respect to $K_{S}$ (Fig. 3c). The failure of the Kozeny-Carman could be partly 421 affected by the spatial complexity of the porous medium since only sim- 422 plified structural information is needed for its determination, excluding 423 geometric and topologic data (Chen et al., 2008; Valdes-Parada et al., 424 2009). a

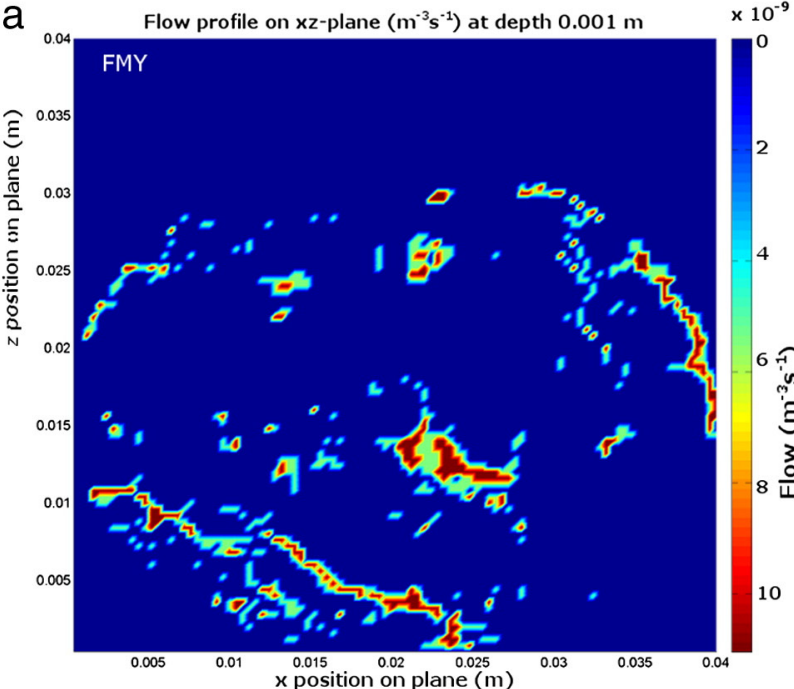

C

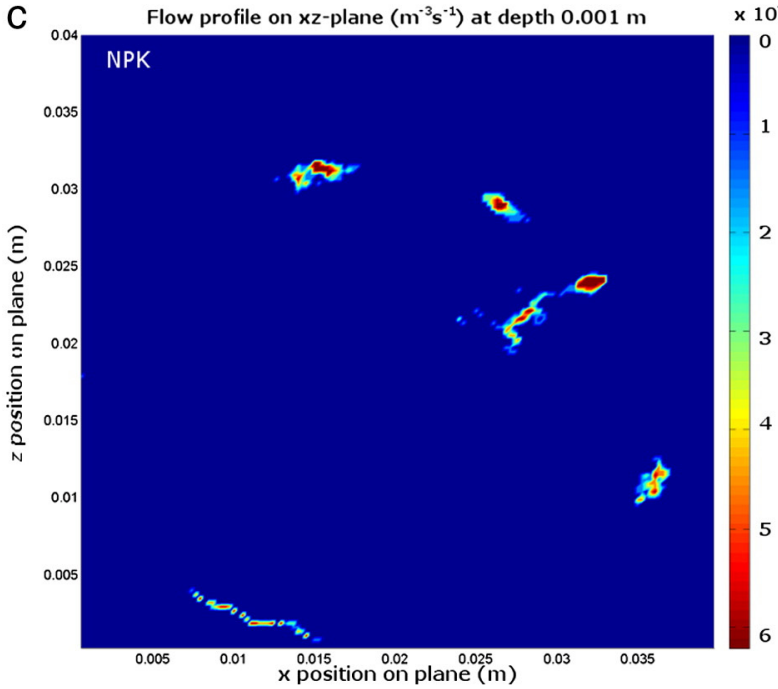

$\times 10^{-9} \mathrm{~b}$

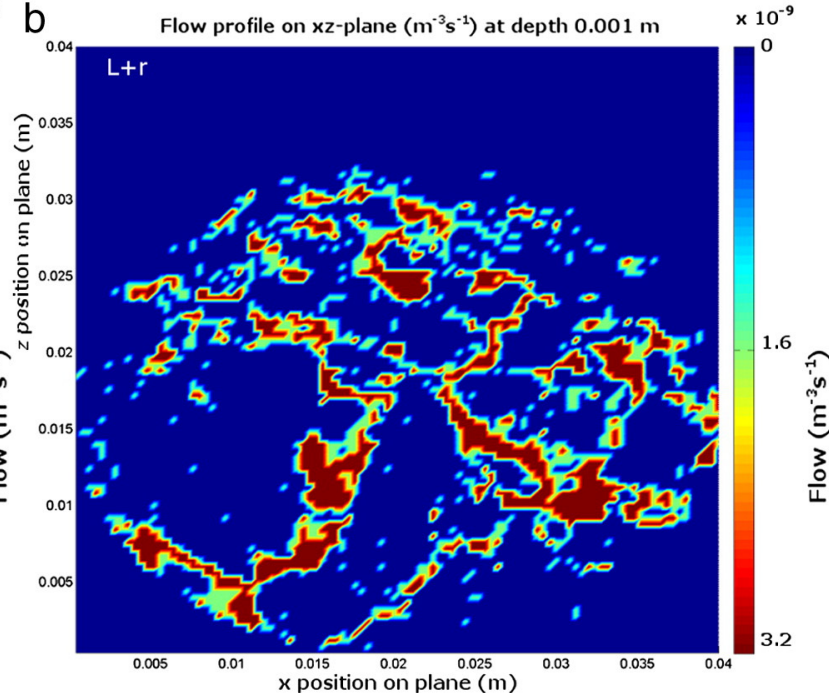

d

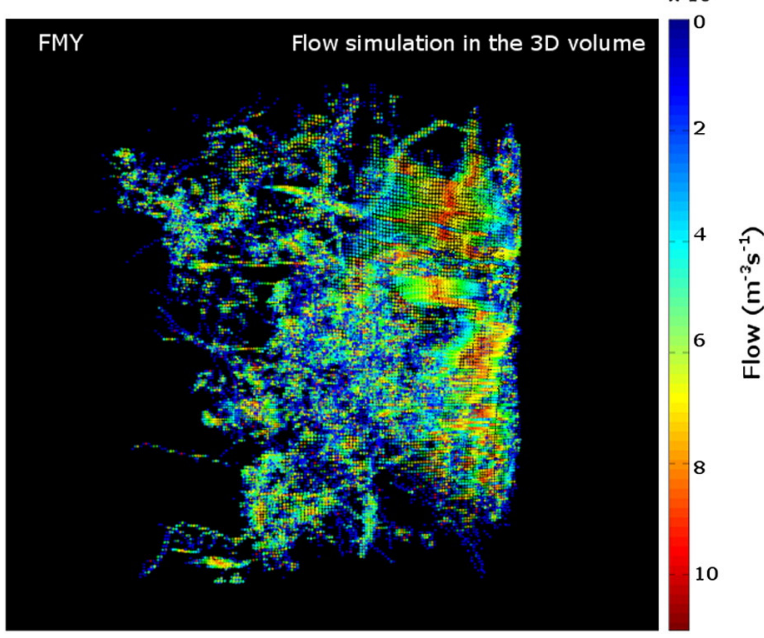

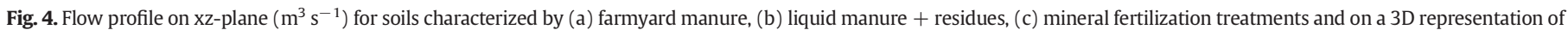
the highly interconnected pore space ( $\mathrm{d}$, farmyard manure) using SPH. 


\section{Conclusions}

Non-invasive acquisition of 3D soil information demonstrated its potential for the study of fluid flow through the pore network. The proposed SPH mesh-free method was able to simulate the water dynamics on large-sized complex samples with a good estimate of hydraulic conductivity values within the same order of magnitude of the experimental ones. The similarities between $\mathrm{K}_{\mathrm{SPH}}$ and experimental data confirmed the major role of large conductive pores on the fluid flow, although a higher scanning resolution would have probably improved the water flow prediction. This was supported by the fact that microCT analysis was limited to pores larger than $40 \mu \mathrm{m}$, excluding the small connections from modelled conduction phenomena. A major role on $\mathrm{K}_{\text {MORPHO }}$ estimate was given by total porosity and pore size distribution, while the pore morphologic features played only a marginal role to influence water conductivity both for $\mathrm{K}_{\mathrm{SPH}}$ and $\mathrm{K}_{\mathrm{MORPHO}}$. We hypothesized that pore morphology, although being able to affect the water flow through porous media, had here a secondary role in the definition of water conduction phenomena due to the presence of unique large macropore and a lack of variability in soils with similar texture properties. Expanding the present method to other soil types as well as increasing the spatial resolution are fundamental requirements to better understand the role of microporosity and the extent of representativeness of a massive singular pore on water conductivity.

\section{References}

Andrä, H., Combaret, N., Dvorkin, J., Glatt, E., Han, J., Kabel, M., Keehm, Y., Krzikalla, F., Lee, M., Madonna, C., 2013. Digital rock physics benchmarks-part II: computing effective properties. Comput. Geosci. 50, 33-43.

Arya, L.M., Heitman, J.L., Thapa, B.B., Bowman, D.C., 2010. Predicting saturated hydraulic conductivity of golf course sands from particle-size distribution. Soil Sci. Soc. Am. J. $74,33-37$.

Bear, J., 1972. Dynamics of Fluids in Porous Media. Elsevier, NY.

Bear, J., Bachmat, Y., 1990. Introduction to Modeling of Transport Phenomena in Porous Media. Kluwer, Dordrecht.

Beven, K., Germann, P., 1982. Macropores and water flow in soils. Water Resour. Res. 18, $1311-1325$

Blunt, M.J., Bijeljic, B., Dong, H., Gharbi, O., Iglauer, S., Mostaghimi, P., Paluszny, A., Pentland, C., 2013. Pore-scale imaging and modelling. Adv. Water Resour. 51, $197-216$.

Bouma, J., 1989. Using soil survey data for quantitative land evaluation. Adv. Soil Sci. 9, $177-213$.

Brewer, R., 1964. Fabric and Mineral Analysis of Soils. John Wiley, New York.

Bribiesca, E., 2000. A measure of compactness for 3D shapes. Comput. Math. Appl. 40, $1275-1284$.

Bribiesca, E., 2008. An easy measure of compactness for 2D and 3D shapes. Pattern Recogn. 41, 543-554.

Bribiesca, E., Jimenez, J.R., Medina, V., Valdes, R., Yanez, O., 2003. A voxel-based measure of discrete compactness for brain imaging. Proceedings of the 25th Annual International Conference of the IEEE EMBS, Cancun, Mexico, pp. 910-913.

Chapuis, R.P., 2012. Predicting the saturated hydraulic conductivity of soils: a review. Bull. Eng. Geol. Environ. 71, 401-434

Chen, C., Packman, A.I., Gaillard, J.F., 2008. Pore-scale analysis of permeability reduction resulting from colloid deposition. Geophys. Res. Lett. 35, 1-5.

Dal Ferro, N., Charrier, P., Morari, F., 2013. Dual-scale micro-CT assessment of soil structure in a long-term fertilization experiment. Geoderma 204, 84-93.

Doube, M., Kłosowski, M.M., Arganda-Carreras, I., Cordelières, F.P., Dougherty, R.P., Jackson, J.S., Schmid, B., Hutchinson, J.R., Shefelbine, S.J., 2010. BoneJ: free and extensible bone image analysis in ImageJ. Bone 47, 1076-1079.

Elliot, T.R., Reynolds, W.D., Heck, R.J., 2010. Use of existing pore models and X-ray computed tomography to predict saturated soil hydraulic conductivity. Geoderma 156 $133-142$.
FAO-UNESCO, 1990. Soil Map of the World. Revised Legend. FAO, Rome.

Hunt, A.G., Ewing, R.P., Horton, R., 2013. What's wrong with soil physics? Soil Sci. Soc. Am. 487 J. 77, 1877-1887.

Jarvis, N.J., 2007. A review of non-equilibrium water flow and solute transport in soil 489 macropores: principles, controlling factors and consequences for water quality. Eur. 490 J. Soil Sci. 58, 523-546.

Kozeny, J., 1953. Hydraulik: Ihre Grundlagen und praktische anwendung. Springer, 492 Vienna.

Larsbo, M., Koestel, J., Jarvis, N., 2014. Relations between macropore network characteris- 494 tics and the degree of preferential solute transport. Hydrol. Earth Syst. Sci. 18, 495 5255-5269.

Lee, T.C., Kashyap, R.L., Chu, C.N., 1994. Building skeleton models via 3-D medial surface/ 497 axis thinning algorithms. CVGIP: Graph. Model Image Process. 56, 462-478. 498

Leij, F.J., Alves, W.J., Van Genuchten, M.T., Williams, J.R., 1996. Unsaturated soil hydraulic 499 database, UNSODA 1.0 user's manual. Rep. EPA/600/R96/095. USEPA, Ada, OK. $\quad 500$

Lilly, A., 1996. A description of the HYPRES database (Hydraulic Properties of European 501 Soils). In: Bruand, A., Duval, O., Wosten, J.H.M., Lilly, A. (Eds.), The Use of Pedotransfer 502 Functions in Soil Hydrology Research. Proc. Workshop of the Project Using Existing 503 Soil Data to Derive Hydraulic Parameters for Simulation Modelling in Environmental 504 Studies and in Land Use Planning. Orleans, France, pp. 161-184. 505

Liu, G.R., Liu, M.B., 2003. Smoothed Particle Hydrodynamics: A Meshfree Particle Method. 506 World Scientific Publishing Co., Singapore. 507

Liu, M.B., Liu, G.R., 2010. Smoothed particle hydrodynamics (SPH): an overview and re- 508 cent developments. Arch. Comput. Methods Eng. 17, 25-76. 509

Luo, L., Lin, H., Li, S., 2010. Quantification of 3-D soil macropore networks in different soil 510 types and land uses using computed tomography. J. Hydrol. 393, 53-64. 511

Maidment, D.R., 1993. Handbook of Hydrology. McGraw-Hill Inc., NY. 512

Monaghan, J.J., 1992. Smoothed particle hydrodynamics. Annu. Rev. Astron. Astrophys. 513 30, 543-574

Morari, F., 2006. Drainage flux measurement and errors associated with automatic 515 tension-controlled suction plates. Soil Sci. Soc. Am. J. 70, 1860-1871. 516

Morari, F., Lugato, E., Berti, A., Giardini, L., 2006. Long-term effects of recommended man- 517 agement practices on soil carbon changes and sequestration in north-eastern Italy. 518 Soil Use Manage. 22, 71-81.

Narsilio, G.A., Buzzi, O., Fityus, S., Yun, T.S., Smith, D.W., 2009. Upscaling of Navier-Stokes 520 equations in porous media: theoretical, numerical and experimental approach. 521 Comput. Geotech. 36, 1200-1206.

Ovaysi, S., Piri, M., 2010. Direct pore-level modeling of incompressible fluid flow in porous 523 media. J. Comput. Phys. 229, 7456-7476. 524

Pachepsky, Y.A., Rawls, W.J., Lin, H.S., 2006. Hydropedology and pedotransfer functions. 525 Geoderma 131, 308-316.

Peng, S., Marone, F., Dultz, S., 2014. Resolution effect in X-ray microcomputed tomogra- 527 phy imaging and small pore's contribution to permeability for a Berea sandstone. 528 J. Hydrol. 510, 403-411.

Rawls, W.J., Gimenez, D., Grossman, R., 1998. Use of soil texture, bulk density, and slope of 530 the water retention curve to predict saturated hydraulic conductivity. Trans. ASAE 41, 531 983-988.

Remy, E., Thiel, E., 2002. Medial axis for chamfer distances: computing look-up tables and 533 neighbourhoods in 2D or 3D. Pattern Recogn. Lett. 23, 649-661. 534

Reynolds, W.D., Elrick, D.E., Youngs, E.G., Amoozegar, A., Booltink, H.W.G., Bouma, J., 2002. 535 3.4 Saturated and field-saturated water flow parameters. Methods of Soil Analysis 536 Part 4 - Physical Methods. Dane J.H.; Topp, G.C., Madison, WI, pp. 797-801. 537

Serra, J., 1982. Image Analysis and Mathematical Morphology. Academic Press, London. 538 Strozzi, A.G., Duwig, C., Marquez, J., Prado, B., Delmas, P., Trujillo, F., Gamage, P., 2009. 3D 539 porous media liquid-solid interaction simulation using SPH modeling and tomo- 540 graphic images. MVA2009 IAPR Conference on Machine Vision Applications, Yokoha- 541 ma, Japan, pp. 328-331.

Tartakovsky, A.M., Meakin, P., 2005. Simulation of unsaturated flow in complex fractures 543 using smoothed particle hydrodynamics. Vadose Zone J. 4, 848-855.

Valdes-Parada, F.J., Ochoa-Tapia, J.A., Alvarez-Ramirez, J., 2009. Validity of the permeabil- 545 ity Carman-Kozeny equation: a volume averaging approach. Physica A 388, 789-798. 546

Van Genuchten, M.T., Leij, F., Yates, S., 1991. The RETC code for quantifying the hydraulic 547 functions of unsaturated soils. EPA/600/2-91/065. R.S. Kerr Environmental Research 548 Laboratory, USEPA, Ada, OK.

Vereecken, H., Weynants, M., Javaux, M., Pachepsky, Y., Schaap, M.G., van Genuchten, 550 M.T., 2010. Using pedotransfer functions to estimate the van Genuchten-Mualem 551 soil hydraulic properties: a review. Vadose Zone J. 9, 795-820.

Wösten, J.H.M., Pachepsky, Y.A., Rawls, W.J., 2001. Pedotransfer functions: bridging the gap between available basic soil data and missing soil hydraulic characteristics. J. Hydrol. 251, 123-150. 